
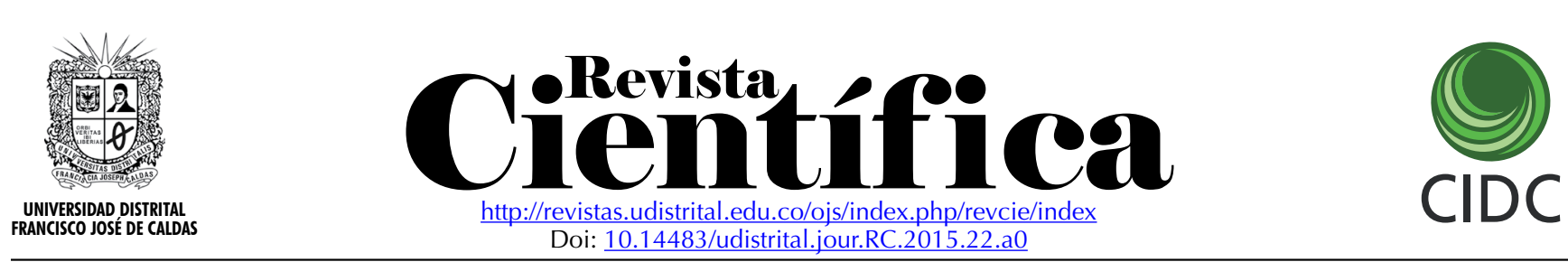

CARTA AL EDITOR

\title{
Ciencia de la sostenibilidad Una revolución científica a la que quiere contribuir Revista Científica
}

\author{
Daniel Gil Pérez ${ }^{1}$ \\ Amparo Vilchez ${ }^{1}$
}

Es una integración necesaria, debido a la estrecha relación de los problemas que pretende resolver (Duarte, 2006; Vilches \& Gil, 2013; Diamond, 2006), como el agotamiento de recursos esenciales, la contaminación que está degradando los ecosistemas, la explosión demográfica que ha sobrepasado la capacidad de carga del planeta, el desajuste climático, la pérdida de la diversidad biológica y cultural, las desigualdades inaceptables o conflictos, y las distintas violencias, fruto de un sistema socioeconómico insolidario que está orientado a la búsqueda del máximo beneficio particular a corto plazo.

La ciencia de la sostenibilidad surge como una manera de comprender la estructura, cada vez más compleja, constituida por las sociedades humanas y los sistemas naturales de los que hacen parte y con los que interactúan. Un abordaje sistémico de este tipo de relaciones le otorga a esta ciencia tres características fundamentales:

- Es profundamente interdisciplinar, pues aborda desafíos complejos que incluyen problemas de diversa índole que están estrechamente vinculados, por lo que no se pueden resolver de manera aislada.

- Es transdisciplinar porque incorpora a ciudadanas y ciudadanos en los procesos de investigación y toma de decisiones. Aunque muchos de ellos no hacen parte del ámbito académico, sus objetivos, conocimientos y capacidad de intervención resultan imprescindibles para definir y desarrollar estrategias viables.
- Tiene una perspectiva glocal -global y local a la vez- que considera el corto, mediano y largo plazo al formular estrategias de intervención que anticipen posibles riesgos y obstáculos, y aprovechen tendencias positivas.

Enfoques con esas características permiten evitar las contradicciones que a menudo surgen durante la formulación e implementación de medidas orientadas a resolver problemas en una época y un lugar específicos. Tienen presente la conexión que existe entre diversos problemas.

El heliocentrismo y la mecánica newtoniana unificaron cielo y tierra; el evolucionismo estableció la relación entre la especie humana y los demás seres vivos. En la actualidad, se ha iniciado una revolución científica que se caracteriza por la integración del desarrollo social (económi$\mathrm{co}$, industrial, cultural, etc.) con los procesos del mundo natural para comprender las interacciones entre los dos y hacer posible la transición hacia la sostenibilidad.

Esta nueva área de conocimiento se está desarrollando de manera impresionante. Se ha incorporado como nueva disciplina en un buen número de universidades, se están organizando múltiples encuentros internacionales para crear espacios de discusión y se han creado medios de expresión en los que se publican anualmente miles de artículos, con un notable crecimiento exponencial (Kajikawa, Ohno, Takeda, Matsushima, \& Komiyama, 2007; Bettencourt \& Kaur, 2011).

Sin embargo, la ciencia de la sostenibilidad es ignorada fuera del círculo que la ha impulsado

Profesores de la Universidad de Valencia, España. Contacto: Daniel.Gil@uv.es 
como disciplina durante casi tres lustros de existencia. Tal situación ha limitado su objetivo fundamental de contribuir para que haga una transición hacia la sostenibilidad, como lo confirman investigadores de distintas áreas y revistas internacionales. Como tiene poca influencia en el resto de la comunidad científica y en los movimientos sociales, no puede desarrollar plenamente los principios de inter y transdisciplinariedad que la caracterizan.

Es evidente que una profunda revolución científica que pueda integrar el estudio del desarrollo social y de los procesos naturales no se garantiza solamente con la creación de una nueva área de conocimiento. Así que la ciencia de la Sostenibilidad debe definir una nueva orientación que influya en otras disciplinas al reflexionar sobre las repercusiones socioambientales que éstas tienen a corto, mediano y largo plazo. Para que esto suceda, es preciso estudiar los aportes de otros campos, la perspectiva de los movimientos ciudadanos y las diferentes actividades sociales (de corporaciones, sindicatos, medios de comunicación, políticos, etc.).

Hoy, por ejemplo, no tiene sentido discutir sobre la extracción de hidrocarburos mediante la tecnología de la fractura hidráulica o fracking sin hacer un análisis exhaustivo sobre sus consecuencias socioambientales, junto con distintos sectores de la comunidad científica y con movimientos ciudadanos que se ven afectados de forma directa o indirecta. Un estudio que se basara en la importancia de reducir la dependencia exterior al obtener recursos energéticos puede concluir que el fracking es una buena opción (esto afirman numerosos informes y propuestas que difunden los medios de comunicación). Sin embargo, no consideraría las consecuencias sobre el territorio, sus efectos en la salud humana, su contribución al cambio climático, etc. De igual manera, evidenciaría que los beneficios particulares y a corto plazo priman sobre el bienestar colectivo y se desviaría la inversión necesaria para impulsar energías renovables y limpias, la única solución sostenible ante el problema energético.
La ciencia de la sostenibilidad considera las exigencias de inter y transdisciplinariedad, junto con los planteamientos glocales, en una amplia perspectiva temporal a fin de influir en el trabajo de los profesionales de cualquier área, la enseñanza de las distintas disciplinas, la educación ciudadana y la acción política que orienta el desarrollo social. No es suficiente con crear una nueva disciplina; se requiere un cambio de paradigma que afecte el conjunto de las actividades sociales. Solo así será posible participar en la transición hacia la sostenibilidad.

La Revista Científica se suma al Ilamado que se le ha hecho a la comunidad científica y a los movimientos sociales para desarrollar una ciencia que contribuya a la urgente superación de la actual emergencia planetaria y posibilite la transición hacia la sostenibilidad.

\section{Referencias Bibliográficas}

Bettencourt, L., \& Kaur, J. (2011). Evolution and Structure of Sustainability Science. Proceedings of the National Academy of Sciences, 19540-19545.

Diamond, J. (2006). Colapso. Barcelona: Debate.

Duarte, C. (. (Ed.). (2006). Cambio Global. Impacto de la actividad humana sobre el sistema tierra. Madrid: CSIC.

Kajikawa, Y., Ohno, J., Takeda, Y., Matsushima, K., \& Komiyama, H. (2007). Creating an Academic Landscape of Sustainability Science: An Analysis of the Citation Network. Sustainability Science, 2, 221-231.

Kates, R., Clark, W., Corell, R., Hall, J., Jaeger, C., Lowe, I., y otros. (2001). Sustainability Science. Science, 292(5517), 641-642.

Lubchenco, J. (1998). Entering the Century of the Environment: A New Social Contract for Science. Science, 279, 491-497.

Vilches, A., \& Gil, D. (2013). Ciencia de la Sostenibilidad: Un nuevo campo de conocimientos al que la Química y la Educación Química están contribuyendo. Educación Química, 24(2), 199-206. 